\title{
Patient Experiences When Preparing for Discharge Home after Total Knee Replacement
}

\author{
Renee Causey-Upton \\ Eastern Kentucky University, renee.causey-upton@eku.edu \\ Dana M. Howell \\ Eastern Kentucky University, dana.howell@eku.edu
}

Follow this and additional works at: https://nsuworks.nova.edu/ijahsp

Part of the Occupational Therapy Commons, and the Physical Therapy Commons

\section{Recommended Citation}

Causey-Upton R, Howell DM. Patient Experiences When Preparing for Discharge Home after Total Knee Replacement. The Internet Journal of Allied Health Sciences and Practice. 2017 Jan 01;15(1), Article 5.

This Manuscript is brought to you for free and open access by the College of Health Care Sciences at NSUWorks. It has been accepted for inclusion in Internet Journal of Allied Health Sciences and Practice by an authorized editor of NSUWorks. For more information, please contact nsuworks@nova.edu. 


\title{
Patient Experiences When Preparing for Discharge Home after Total Knee Replacement
}

\begin{abstract}
Purpose: Following total knee replacement (TKR), patients must prepare quickly for discharge to home via education and rehabilitation. Patient needs may not fully be met prior to discharge after TKR surgery. The purpose of this descriptive study using transcendental phenomenology methods was to understand patients' experiences when preparing to return home after TKR surgery. Method: Data was collected using semi-structured interviews that occurred 1 to 2 days prior to discharge in patients' hospital rooms. Four participants were interviewed prior to discharge and interviews were transcribed verbatim for data analysis. Data analysis and data collection were concurrent, permitting subsequent interviews to be altered as needed based on results from previous participants. Thematic analysis of the interview transcriptions was conducted to identify significant meaning statements through a process of horizonalization. Significant statements were organized into shared themes among participants. Results: Three themes emerged: being supported for discharge home; having confidence in self, family and health care staff; and persevering: overcoming obstacles. Participants overall felt prepared for their surgery and the postoperative phase. The following factors increased readiness for discharge: having prior positive experience with TKR through the experiences of others, attending pre-operative education, interacting with knowledgeable staff, and having the appropriate support at home. Some patients were unprepared for the amount of pain they experienced after surgery. Conclusions/Recommendations: Health care providers should educate patients about safety for the home environment, adaptive techniques for functional tasks, and when to resume normal activities at home. Other implications include encouraging patients to attend pre-operative education, addressing patients' previous experiences with TKR, both positive and negative, as well as providing realistic information regarding pain after surgery.
\end{abstract}

\section{Author Bio(s)}

Renee Causey-Upton, OTD, MS, OTR/L, has a doctorate in Occupational Therapy from Chatham University and is an assistant professor in the Department of Occupational Science and Occupational Therapy at Eastern Kentucky University. This study was completed to fulfill requirements toward a $\mathrm{PhD}$ in Rehabilitation Sciences at University of Kentucky. Dana M. Howell, PhD, OTD, OTR/L has a PhD in Education from the University of Idaho and is a full professor in the Department of Occupational Science and Occupational Therapy at Eastern Kentucky University. She is also the Occupational Therapy Doctorate Program Coordinator at Eastern Kentucky University and Rehabilitation Sciences Doctoral program Liaison at University of Kentucky.

\section{Acknowledgements}

The authors would like to thank Laura Barnhart, OTR/L, Sarah Clifton, MS, OTR/L, Jerri Crager, OTR/L, Gretchen Roentz, OTR/L, and Saint Joseph East Hospital for their support of this research. Note to editor: All individual therapists listed above as well as the VP of Patient Care/Chief Nursing Officer of Saint Joseph East Hospital provided permission to be listed in the Acknowledgements section of this article. 


\title{
IJAHSP \\ The Internet Joưnal of Allied Health Sciences and Practice
}

Dedicated to allied health professional practice and education

Vol. 15 No. 1 ISSN 1540-580X

\section{Patient Experiences When Preparing for Discharge Home after Total Knee Replacement}

\author{
Renee Causey-Upton, OTD, MS, OTR/L \\ Dana M. Howell, PhD, OTD, OTR/L \\ Eastern Kentucky University \\ United States
}

\begin{abstract}
Purpose: Following total knee replacement (TKR), patients must prepare quickly for discharge to home via education and rehabilitation. Patient needs may not fully be met prior to discharge after TKR surgery. The purpose of this descriptive study using transcendental phenomenology methods was to understand patients' experiences when preparing to return home after TKR surgery. Method: Data were collected using semi-structured interviews that occurred 1 to 2 days prior to discharge in patients' hospital rooms. Four participants were interviewed prior to discharge and interviews were transcribed verbatim for data analysis. Data analysis and data collection were concurrent, permitting subsequent interviews to be altered as needed based on results from previous participants. Thematic analysis of the interview transcriptions was conducted to identify significant meaning statements through a process of horizonalization. Significant statements were organized into shared themes among participants. Results: Three themes emerged: being supported for discharge home; having confidence in self, family, and health care staff; and persevering: overcoming obstacles. Participants overall felt prepared for their surgery and the post-operative phase. The following factors increased readiness for discharge: having prior positive experience with TKR through the experiences of others, attending pre-operative education, interacting with knowledgeable staff, and having the appropriate support at home. Some patients were unprepared for the amount of pain they experienced after surgery. Conclusions/Recommendations: Healthcare providers should educate patients about safety for the home environment, adaptive techniques for functional tasks, and when to resume normal activities at home. Other implications include encouraging patients to attend pre-operative education, addressing patients' previous experiences with TKR, both positive and negative, as well as providing realistic information regarding pain after surgery.
\end{abstract}

\section{INTRODUCTION}

More than 750,000 knee replacement surgeries are performed annually in the United States. ${ }^{1}$ The number of persons projected to undergo total knee replacement (TKR) surgery each year in the United States is expected to increase to 1,375,574 in 2020.2 Hospital stays following TKR surgery are shorter, resulting in discharge from the hospital while patients are still in an acute phase of recovery. ${ }^{3}$ This means that following TKR, patients must be prepared for discharge, via education and rehabilitation, within increasingly shorter timeframes.

Following discharge after TKR, some patients experience poor outcomes including reduced function, incidence of falls, and hospital readmissions. Patients have reported being unprepared for the limitations they experienced after surgery as well as having difficulty completing daily life tasks in their home environment. ${ }^{4-5}$ Incidence of falling in the months after TKR have been reported to be $4.3 \%$ to as high as $11.8 \%, 6,7$ These numbers are significant as falls can lead to severe injury, declines in function, as well as hospital readmission. A 5\% readmission rate was found for patients who underwent TKR between 2007 and 2010 in the United States. ${ }^{8}$ These sub-optimal outcomes may indicate reduced preparedness for recovery at home following the acute phase after TKR.

In addition to quantitative evidence of poor readiness for discharge home after TKR surgery, patients have qualitatively identified areas of concern that were not fully addressed prior to discharge home following joint replacement. Unrealistic expectations have been reported about the activities patients would be able to complete after discharge as well as difficulty with role reversals while spouses were recovering from total joint replacement. ${ }^{5}$ Decreased functional independence has been reported frequently in the

(C) The Internet Journal of Allied Health Sciences and Practice, 2017 
literature as a concern after patients were discharged home following TKR.4,-10 Barksdale and Backer examined health-related stressors experienced by patients 7 days after being discharged home following TKR surgery. ${ }^{9}$ Participants identified several areas of concern post-surgery, such as pain levels, decreased independence with functional transfers, and increased dependency on family members. Another study found similar results when examining patient experiences of outcomes following TKR. ${ }^{10}$ Overall participants reported positive outcomes, but concerns were identified by these patients related to pain and limitations in mobility. Some patients have also had confusion regarding discharge recommendations after returning to home, even though instructions initially seemed clear in the hospital setting. ${ }^{4}$ Research demonstrates that patient needs are not fully met for discharge home from the acute care setting.

Discharge outcomes following TKR are significant as they impact initial discharge placement and patient safety in the early postoperative phase. Most patients discharge home after surgery, however some persons may require additional care and therapy services in other environments after TKR. ${ }^{8}$ The home environment is the most complex discharge setting in the early phase after surgery because patients have less time available to increase function prior to discharge and less time to prepare along with their caregivers for any alterations in their function. The home environment can also be fraught with many physical barriers that pose safety hazards that can lead to falls. In addition, patients do not have the same access to health care providers that they experienced while in the hospital to readily answer questions and respond to concerns. ${ }^{4}$ Appropriate discharge preparation is a necessity for patients who are going home after TKR rather than to an inpatient setting for additional healthcare services.

Discharge preparation following TKR has not been examined thoroughly from a qualitative perspective; however, some studies have quantitatively examined factors that are associated with length of stay following TKR. Medical issues after surgery and lack of social support at home were consistently related to increased length of stay after knee replacement. 11-13 The literature also demonstrates factors that can reduce length of stay following TKR. Early mobilization of patients as well as providing comprehensive pre-operative education have been found to decrease time in the hospital after TKR surgery. ${ }^{14,15}$ Patients who received local infiltration analgesia during TKR have had better pain relief and shorter hospital length of stay than those patients who did not receive this form of analgesia. ${ }^{16}$

While there is limited research in the current literature about patient experiences of discharge preparation after TKR, we can learn from studies that have qualitatively examined this transition for patients with other diagnoses. A previous study examined perspectives of patients regarding early discharge following total hip replacement (THR) and found that patients hid their apprehensions regarding early discharge, such as the impact of early discharge on family and functional mobility concerns. ${ }^{17}$ When patient experiences of preparing for discharge after THR surgery were studied, factors such as patient confidence and feeling safe were issues that impacted discharge readiness. ${ }^{18} \mathrm{~A}$ recent metasynthesis examined experiences of older adults related to discharge from the hospital after orthopedic surgery or intervention. ${ }^{19}$ Patients' mental outlook was found to both impact and be impacted by pain, limitations in function and activity levels, as well as declines in independence. Three of the 16 articles reviewed did include a population of participants who had undergone TKR surgery; however, none of these studies examined the participants' lived experiences of discharge preparation. Although the experience of preparing for discharge has been examined for patients with THR and other diagnoses, more needs to be known about the transition to home for those who have undergone TKR.

Understanding the experiences of patients as they prepare to return home following TKR will aid rehabilitation professionals to better prepare these clients for discharge home. The purpose of this descriptive study was to describe patients' experiences when preparing for discharge home following elective TKR surgery. Understanding this experience was also anticipated to increase knowledge of factors that may impact subjective readiness for return to home following TKR surgery.

\section{METHODS}

This study was approved by the Institutional Review Board (IRB) at Eastern Kentucky University as well as the Scientific Review Committee at the study setting in September 2014 through an expedited review process. All participants provided informed consent to participate in the study. All ethical procedures for conduct of research were followed throughout the research study.

\section{Research Design}

A descriptive study using transcendental phenomenology methods was conducted. Transcendental phenomenology is a qualitative research approach that seeks to examine the lived experience of a phenomenon for a group of individuals. ${ }^{20}$ Phenomenology is the appropriate technique for this study to reveal the collective perceptions and experiences of preparing for discharge home following TKR surgery. The transcendental approach to phenomenology focuses on the participants' experiences and limits the impact of the investigator on the research process through the use of reflexivity. ${ }^{20-21}$

(C) The Internet Journal of Allied Health Sciences and Practice, 2017 


\section{Study Setting}

The study took place on the orthopedic and medical-surgical units at an acute care hospital in Lexington, Kentucky. This is a 217 bed facility that provides both inpatient and outpatient services. Patients undergoing TKR surgery elect whether or not to attend pre-operative education prior to their surgery. Following surgery, patients receive inpatient physical and occupational therapy services throughout their hospital stay until discharge. Physical therapy services are provided twice daily while patients receive occupational therapy services once per day during their inpatient recovery. Patients typically discharge from the study setting within 1-2 days after TKR, and the majority of these patients discharge home rather than to a subacute setting. Patients may receive either home health or outpatient therapy services after discharge from the hospital. These services typically only consist of physical therapy after the acute care setting, but patients who require further inpatient rehabilitation will also receive occupational therapy if needed.

\section{Recruitment}

Adults who had undergone elective TKR surgery and were receiving inpatient rehabilitation from physical and occupational therapy in an acute care setting were included in this study. Participants had to be 18 years of age or older. Subjects with a diagnosis of dementia as assessed by medical history review and persons who were unable to provide verbal answers in English were excluded from the study due to potential inability to provide the in-depth answers required of an unstructured interview approach. Patients who required TKR due to traumatic injury or avascular necrosis were excluded because a sudden, non-elective surgery could have had a confounding impact on subjective readiness for discharge. Patients with planned discharge to a subacute facility rather than to home from the hospital were not included in the study as this could impact participant planning processes and views of upcoming discharge from the hospital. Patients who had undergone TKR surgery previously were excluded initially from the study to avoid the impact of prior joint replacement experience on readiness for discharge. Alterations were later made to the research protocol, with IRB approval, to allow those with prior joint replacement to take part in the study. However, no participants were recruited for the study who had undergone a previous TKR. While patients from other states sometimes undergo TKR at the study setting, all participants included in the study were residents of Kentucky.

Purposive sampling was used to identify participants. This approach to identifying participants who have experienced the phenomenon being studied is common for research using phenomenological methods. ${ }^{20,22}$ The occupational therapist on the orthopedic and medicalsurgical units served as a gatekeeper to identify eligible participants during the occupational therapy evaluation. The gatekeepr was trained in the research protocol by the primary researcher for this process. Some participants received their occupational therapy evaluation the day of surgery, but those who had surgery later in the day may not have received their evaluation until post-operative day 1. Potential participants who wanted to learn more about the study gave permission for the occupational therapist to provide their names and contact information to the researcher. The researcher then contacted potential participants via telephone to explain the study in more detail and to schedule a meeting for those who were still interested in participating. The researcher met with participants in their hospital room to obtain written informed consent and begin data collection. Patients received a copy of their signed informed consent letter. Participants were informed that participation was voluntary and could be discontinued at any time.

\section{Data Collection}

Semi-structured interviews were used to explore participants' experiences related to preparing for discharge home following TKR and to gain an understanding of what factors impacted their readiness to return home. Interviews began with the following question: How have you prepared for your discharge home related to your total knee replacement sugery? Participants were also asked questions about preparing before and after surgery for discharge, any experiences that made them feel more or less prepared for returning home after surgery, as well as any further arrangements or plans for discharging home from the hospital. Additionally, participants were asked about what was most and least helpful in preparing for discharge home (i.e. people, resources, information) as well as anything else patients experienced while preparing for discharge that had not already been discussed. The same interview protocol consisting of 11 questions was used as a guide for each participant's interview. Follow-up questions were asked as needed based on individual patient responses. Interviews occurred within 1-2 days prior to discharge home from the hospital and took place in participants' hospital rooms. Interviews occurred individually with each participant and lasted approximately 30 to 45 minutes in the evening to avoid interfering with nursing and therapy interventions during the day, unless another time was selected by the participant. Following each interview, the researcher recorded brief field notes related to the setting of the interview and emotional responses of the participant to add context to the interview transcription.

\section{Data Analysis}

Interviews were audio recorded and later transcribed verbatim after the interview was completed by the primary researcher. Data analysis occurred concurrently with data collection procedures as the primary researcher began analysis of completed transcriptions while still gathering data through subsequent participant interviews. Individual transcripts were read completely to obtain initial impressions. Knowledge obtained from previous interviews were used to guide subsequent participant interviews. Non-repeating significant statements were identified from each interview transcript through Moustakas' process of horizonalization.

(C) The Internet Journal of Allied Health Sciences and Practice, 2017 
Horizonalization involved listing significant statements end to end with no hierarchy to reveal the range of perceptions regarding the experience of preparing for discharge after TKR. ${ }^{21}$ Significant statements were labeled as formulated meanings and then clustered into meaning units or themes as they emerged from the participants' words. These meaning units were then refined to develop the final study themes.

\section{Trustworthiness}

Several methods were employed to ensure trustworthiness. The primary researcher maintained a reflexive journal to bracket out prior experiences with the phenomenon and to record thoughts and feelings during the research process. Prior to data collection, the first author recorded preconceived ideas or areas of concern that could impact the research process in order to increase her awareness and ability to limit their impact on the study's results. Examples of information recorded included the belief that occupational therapy could increase readiness for discharge home and the need to remain objective if participants discussed health care providers that the primary investigator knew from working at the study setting. Another important area was the need to disclose to participants the many roles of the primary researcher that related to the research study including being a PRN (working as needed) occupational therapist at the study setting, being a doctoral student, and also being a professor of occupational therapy. Journaling was also completed after each interview to record initial thoughts and impressions about the experiences of each participant that were later used to refer back to during the data analysis process.

An audit trail was maintained to describe the research process in detail and to retain a record of how decisions were made throughout the study. The integrity of research data was maintained by beginning a new document for individual participants at each step in the research process before later compiling the data for all participants together in a single document. This allowed the researcher to refer back to original documents to ensure a thorough and accurate analysis. Member checking was conducted to ensure that results were reflective of participants' experiences. A hard copy of the transcript was not provided to the participant in order to maintain the integrity of the verbatim transcription; rather the emerging themes were confirmed by the participant to be reflective of the discharge preparation experience. ${ }^{23}$ Brief field notes were recorded during interviews about the physical environment of the participant's room as well as the behavior and body language of each participant. These notes were referred back to during data analysis and confirmed the patient's demeanor that was both heard in the interview recording and read in the words of each transcript. Peer review was also completed between the first and second author to confirm the findings and decisions made throughout the research process.

\section{RESULTS}

There were four participants, three women and one man, ranging in age from 55 to 80 years old. A common sample size for phenomenology research ranges from 1-10 participants. ${ }^{20,22}$ All participants were discharging home with a family member after surgery and are identified here by pseudonyms. Participants were interviewed the day of surgery, or on the first post-operative day following TKR. Three of the four participants (Joseph, Samantha, and Janice) had a spouse or family member who had previously had a TKR. Only Ruth had no prior experience with TKR.

Table 1: Participants

\begin{tabular}{|c|c|c|}
\hline Pseudonym & Gender & TKR Experience \\
\hline Ruth & Female & $\begin{array}{ll}- & \text { 1st TKR } \\
- & \text { No prior experience }\end{array}$ \\
\hline Joseph & Male & $\begin{array}{ll}- & 1 \text { st TKR } \\
- & \text { Experience through spouse's } \\
& \text { previous TKR }\end{array}$ \\
\hline Samantha & Female & $\begin{array}{ll}- & \text { 1st TKR } \\
- & \text { Experience through spouse's and } \\
& \text { brother'sprevious TKR }\end{array}$ \\
\hline Janice & Female & $\begin{array}{ll}- & \text { 1st TKR } \\
- & \text { Experience thorugh sister's previous } \\
& \text { TKR }\end{array}$ \\
\hline
\end{tabular}

Three themes emerged from the data: being supported for discharge home; having confidence in self, family and health care staff; and persevering: overcoming obstacles. Themes and subthemes are presented below in table format. These themes are described in detail in the sections that follow with verbatim quotes for support. 
Table 2: Qualitative Themes

\begin{tabular}{|l|r|}
\hline \multicolumn{1}{|c|}{ Theme } & \multicolumn{1}{c|}{ Sub-themes } \\
\hline Being Supported for Discharge Home & - Needing Assistance for Discharge Home \\
& - Feeling Safe for Discharge Home and In-Hospital \\
\hline Having Confidence in Self, Family and Health Care Staff & - Knowing What to Expect Before Surgery \\
& $\begin{array}{l}\text { - Interacting with Friendly and Knowledgeable Staff } \\
\text { - Having Prior Experience with TKR }\end{array}$ \\
\hline Persevering: Overcoming Obstacles & - Experiencing Pain as Normal \\
& - Handling the Unexpected \\
\hline
\end{tabular}

\section{Being Supported for Discharge Home Needing Assistance for Discharge Home}

Participants overwhelmingly expressed that they would need someone at home with them in the early phase after discharge. Some even stated they could not go home if they did not have assistance. Ruth discussed the importance of having family support at home and said, "My daughter. She is with me every minute, every step of the way. She doesn't have to be there to do everything for me but she, I need somebody right now." She also expressed the following: "I could never go home alone right now. I would have to have somebody, at least somebody there." When Janice was asked how she would feel if she did not have her current support system of her husband and daughters at home she said "l'd be scared alright."

Some participants expressed that they were more secure because their caregiver had previously undergone TKR surgery and would therefore be more prepared to provide them with the proper assistance after discharge. Samantha said the following: "And, I mean, he knows what it is so he knows how to help me. And, uh, take care of me so I feel more secure there. Cause he's been down the road and he knows what it's like." It was reassuring to participants when their caregiver had already experienced TKR surgery and this made them feel more prepared for their own discharge home.

\section{Feeling Safe for Discharge Home and In-Hospital}

Participants discussed the importance of being safe at home as part of their discharge preparation. This included having another person with them at home, but also ensuring that the physical environment was safe for mobility after discharge. Ruth described her plans to go home with her daughter because her home was "all on one, one level. And still you don't have to take a step which is good because I will be using a walker. And, you don't do steps too good with a walker."

In addition to ensuring that participants could access living areas on lower level floors, participants also expressed concern about other aspects of safety such as tripping hazards in the home. Joseph stated: "Rugs. Carpeting, not carpeting that's fastened down, but they are loose, they could possibly slip. And extension cords. Anything like these we might trip over. Like I say looking to get to the house of what you need to watch out for, this kind of stuff that is really quite important there." Patients were aware of aspects of the physical environment that could potentially lead to falls and had made plans to address these.

Participants also discussed the importance of being safe and supported while in the hospital setting. This included getting assistance when needed and recognizing efforts by staff members to keep patients safe by reducing fall risks. Samantha stated: "They come when the call bell's on, and, my husband sat there and he said if I have my other knee done it's going to be here. He said, he said this hospital is wonderful... If something goes wrong you're going to be taken care of." Her spouse felt comfortable enough to go home for an evening while she was in the hospital because of the level of care she received following her TKR surgery. Another participant talked about the need for assistance with transfers while in the hospital. Joseph said "I do not get up out of this chair or out of that bed until one of the nurses is in here. And they put that strap around me and they hold on to it. And I can get up and walk." He also discussed the use of pressure alarms to ensure that patients did not forget to ask for help before getting up and that nursing implemented these devices to avoid falls.

\section{Having Confidence in Self, Family and Health Care Staff Knowing What to Expect Before Surgery}

The majority of participants attended their own preoperative education course or had attended the course when their spouse previously underwent TKR surgery. The pre-operative education program at the study setting is interdisciplinary and includes education from the rehabilitation nurse, physical therapist, and case manager. The class includes patients who are undergoing both TKR and total hip replacement and lasts approximately 3 hours. Patients are educated about what to do before surgery, what to expect after surgery, physical and occupational therapy services, adaptive devices for mobility and self-care, as well as home health services for the post-operative phase. Participants in this study reported that attending pre-operative education increased

(C) The Internet Journal of Allied Health Sciences and Practice, 2017 
their confidence by preparing them for the future. Joseph stated: "I really felt that confident of them. After, with talking to the doctor himself, and then talking to, we went to that class about the surgery, and the way they presented it and talked about it, you know with, not pulling, not pulling no punches, it's the way it's going to be, and that's it." Participants also expressed that preoperative education helped them to know what to expect in their recovery process. Samantha stated: "Well they had us come to classes, uh two of them, prior to the surgery. And we went over everything, both before pre-op and post-op, so that pretty much, you know, gave us an idea of what to expect."

Getting questions answered was another aspect that participants identified as being significant within preoperative education. Having family present also increased patients' confidence because another person was aware of recommendations and what to expect following surgery. Ruth said: "But you go to see her a week before your surgery and she answers all your questions and shows you the pictures of what knee replacement is and, and the doctor and their way of doing things. You know what you're doing going into it. And I could take my daughter along with me so she knows too, you know."

Only one participant did not attend preoperative education classes, but she did express that the doctor advised her of what to expect after surgery. She also had learned about the process from the experiences of her sister-in-law who had previously had both knees replaced. When asked about these experiences, Janice stated "Well I knew more of what to expect I think." The combination of education from the physician and having experienced the process through a family member appeared to have prepared Janice for undergoing her own TKR.

\section{Interacting with Friendly and Knowledgeable Staff}

The positive attitudes of staff members and the rapport built between professionals and patients was another factor that instilled confidence among participants. Patients interacted with multiple healthcare providers during their hospital stay including nurses, physical therapists, occupational therapists, nursing assistants, physicians, and case managers. Individual patients may have interacted with additional staff members, such as dieticians, if their personal needs required care from other healthcare providers. This positive rapport was expressed by some participants to be even more important than the surgical process itself. Joseph stated the following: "Ah, well of course there's the skill of the surgeon. But really, I think a lot of it came down to the quality of the nursing care that I've received. And I know, I mean, their attitudes, their friendliness, the, the way they, the way they talk to you. It really, makes me feel good about it." Positive interactions with staff members increased participants' confidence both while in the hospital and as they prepared for discharge home.

Staff were considered to be knowledgeable and thorough in their education and instructions to patients. Participants appreciated the depth of this information and felt that all their needs were met for discharge. Samantha stated: "They've been on top of everything, I mean about the discharge and everything. Even, you know, they've talked to you about nutrition and physical therapy and I mean, they just, they cover everything." Patients did not identify any information that staff failed to cover while they were preparing for their upcoming discharge from the hospital.

\section{Having Prior Experience with TKR}

Participants discussed having confidence related to the TKR process as a result of experiencing this previously, either through a family member or friend. This permitted patients to learn about the recovery process through the experiences of others and made patients feel more prepared for their own recovery post TKR. Overall, having this prior knowledge was a positive experience. Joseph stated: "I'm ready to go. You know, course I guess I am lucky in the fact that my wife had it done 5 weeks ago and I saw how she did it. So that gives me a little more confidence. But I know with her, she was very confident and ready to go."

One participant did express a negative prior experience related to a family member, however her positive experiences with a spouse who previously underwent TKR appeared to outweigh these concerns. Samantha stated the following: "I think the experiences I had with my husband probably, you know. Because we're more ready, I mean we are definitely ready home wise to go. And, so you hear positive and like I said, the only negative was my father, and uh, there's some in the nursing home, where he's at. That, you know, they're usually the more elderly, and my dad, the only thing, he was up walking around doing great, but then he got MRSA [Methicillin-Resistant Staphylococcus Aureus], VRE [Vancomycin-Resistant Enterococci], he had a lot of problems."

One participant reported having confidence in his surgeon because he had undergone a previous orthopedic surgery prior to completing the TKR. This prior surgical experience made the process more familiar even though he was undergoing a different procedure. Joseph said: "Now I did have the fact that this doctor had also, um, prepared my shoulder earlier in the year so I knew how he was and his staff." Another participant had increased confidence in her surgeon because she researched his surgical record and felt that he had performed enough previous surgical procedures that she felt assured of his skills. Samantha stated: "I

(C) The Internet Journal of Allied Health Sciences and Practice, 2017 
researched him because he was a new guy in town from Tennessee. And, uh, I went out and researched him and he had a good record. Cause you never know. You don't know." Samantha also expressed that she would not have felt confident having the doctor perform her surgery if he had not performed the same procedure many times before.

\section{Persevering: Overcoming Obstacles Experiencing Pain as Normal}

Most patients reported that they expected to experience pain following surgery as part of the recovery process. They also expressed that while they would have some pain, they knew that nursing staff would implement procedures to reduce their pain to a tolerable level. Samantha stated: "It's no bed of roses. They don't paint that, you know, that you're gonna be pain free and that it's going to be, you know, very painful, and that it, the more exercises you do preoperative will get you ready for the postop phase." Joseph echoed this by stating "There will be pain. That's all there is to it. They will try their best to control it, but, there's still gonna be some no matter what. And there has been." While pain was not experienced as a positive aspect of recovery toward discharge, participants overall anticipated this as a normal and expected part of TKR. Participants also recognized the need to be actively involved in their care and that the recovery process would not be an easy one. Ruth stated: "Well, I know it's, it's gonna be hard work. But I'm not just going to let it sit there and heal itself." Participants acknowledged that they had a responsibility in their progress after surgery.

\section{Handling the Unexpected}

While most participants expected the recovery process to be difficult, some were unprepared for the pain and complications that followed their surgeries during their hospital stay. When asked if she was prepared for the pain she experienced post-surgically in the hospital, Ruth stated, "No, I thought it was going to be a piece of cake. And it ain't." Samantha experienced some unanticipated complications including significant edema, fever, nausea, and pain. She described her edema as "It, it was going down the front of my, the front of my shin. And, it was in, the effusion was going down that way. He said, you've just got a terrible amount of fluids in there." Initially her pain was well controlled with a nerve block, but pain increased dramatically as the nerve block wore off. Samantha described her experience of the nerve block wearing off as first excitement to regain movement, followed by overwhelming pain. "Yeah, and, and then, and then it's like it's got you. And depending on what time your surgery was that day, that's when it's going to wear off. And the numbness started, my toes, I could start wiggling my toes about 10:00, 10:30. And I thought wow, I've got my toes back, got my toes back! You know, I was thrilled to death, and then about 2:00 I had everything back. I woke up like "ow!" It's like no, no, it's here with a vengeance."

Even when patients did experience complications or pain exceeded their expectations, they did recognize that the condition was temporary and that these issues would resolve. Samantha acknowledged: "This, you know, we'll get through this, we will get through this. I will get through this. That's the way, you know, but it don't come in one day." Samantha needed an extra night in the hospital due to all of her complications, but she accepted this extended stay as a part of her recovery process. Ruth recognized that "you don't just come in here thinking that it's going to be a, a simple little couple days in bed. Huh-uh. You come in here and you work at it." Participants realized that recovery after TKR is not easy, but is instead a necessary step toward discharge and returning to function post-surgery.

\section{Preparing for the Post-Operative Phase}

Participants mentioned several things they did prior to surgery to prepare for their discharge following TKR. While this did not emerge as a theme, the processes were described as ways that clients prepared for the post-surgical phase. Many of these preparations addressed higher level occupations that clients would need to complete after surgery, such as meal preparation and home management tasks. Patients prepared for these occupations by preparing and freezing food in advance, buying soup and other simple meals, cleaning the home and completing laundry prior to surgery, and securing paid assistance for home management tasks post-surgery. Other areas included mobility with an adaptive device, pre-operative exercises for strengthening, and setting up physical therapy services for discharge home.

\section{DISCUSSION}

This study found that persons who underwent TKR had experiences related to wanting to feel safe while in the hospital and upon return to home, having confidence in themselves and others who were involved in their care, as well as overcoming difficult aspects of the recovery process in-hospital. Participants overall felt prepared for their surgery and the post-operative phase.

\section{Needing Social Support}

Support was found to be an important theme for patients who underwent total hip replacement (THR) in previous research, and this is similar to participants in this current study who felt that having someone at home was necessary for discharge. ${ }^{18}$ Participants expressed that they would be reluctant to return home without a caregiver in the early phase after surgery, and considered having

(C) The Internet Journal of Allied Health Sciences and Practice, 2017 
social support to be a necessity for discharge home. Other research has found that having a caregiver at home was a predictor of whether patients were sent home after surgery or to another environment initially; patients were much more likely to discharge to a sub-acute setting if they did not have a caregiver at home. ${ }^{13,24}$ Previous research has also found inadequate social support to be the most significant factor that delays early discharge following primary joint replacement surgery. ${ }^{12}$ Social support should be assessed pre-operatively so that arrangements can be made for patients who live alone or may have limited support at home in order to increase their preparation for discharge.

\section{Wanting to Feel Safe Before and After Discharge}

Feeling safe, both within the hospital and for discharge home, was a major concern for clients in this study. This is similar to concerns expressed by patients who had undergone THR and were preparing for discharge home after surgery. ${ }^{18}$ Participants in both studies felt safe in the hospital and wanted to ensure their safety at home as well. Participants identified having a caregiver present in the home as well as making alterations to the environment to reduce fall risk as ways to increase safety for discharge. Therapists can educate patients on home safety and provide recommendations for modifications, such as training clients in the use of adaptive devices and removing throw rugs as well as other trip hazards, to increase safety in the home environment after TKR surgery.

\section{Having Confidence as a Result of Previous Experiences with TKR}

Participants in this study felt more confident regarding the recovery process because of previous positive experiences with persons who had undergone TKR. Therefore, it may be beneficial to have clients who have already completed TKR surgery come and speak to future patients during pre-operative education classes. This technique has been used post-operatively to lead a support group after TKR; however, this same approach may be useful prior to surgery as well. ${ }^{25}$ Allowing patients to learn from persons who have already experienced TKR, especially if they do not have a family member who has undergone the surgery, may increase readiness for TKR and discharge home as clients feel more prepared for what to expect in the recovery process. It would also be important to discuss any prior negative experiences patients may have had related to TKR surgery, either from their own previous joint replacement or through the experiences of someone they know who has undergone TKR. This could help to allay fears and provide realistic information regarding what patients should expect after surgery.

\section{Receiving Pre-Operative and Post-Operative Education}

Although evidence is mixed regarding the effectiveness of pre-operative education, the participants in this study found it to be helpful. Some systematic reviews have demonstrated limited support for pre-operative education, while other researchers have shown decreased anxiety before surgery, increased readiness for surgery, improvement in pain control after surgery, and minor reductions in length of stay for persons who attended preoperative education. ${ }^{26-31}$ However, other studies have revealed that many patients found preoperative and postoperative education to be insufficient and that it did not prepare them for what to expect postsurgery.32-34 Some patients have noted inconsistency with education provided by different health care professionals, creating uncertainty about which health care instructions to follow at home. ${ }^{32}$ The participants in this study found education before their surgical procedure to be beneficial for increasing their awareness of what to expect after surgery and as a result, this increased their confidence for discharge. Participants also felt they received valuable information after surgery and were well prepared for returning to their homes. Patients should be encouraged to attend pre-operative education to improve readiness for surgery and promote confidence for discharge home. Health care providers should also address important areas of instruction after surgery as well, such as safety, adaptive techniques for completing valued occupations, and when to resume normal activities.

\section{Persevering after TKR}

One study examined patients' and various health professionals' views on outcomes after both THR and TKR. ${ }^{34}$ Many patients felt that clear expectations were not given regarding the amount of pain they would have after surgery. In addition, information on how to prepare for and manage high pain levels was not sufficient. While participants in this study did expect pain and felt that this was a normal part of the recovery process, some were not fully prepared for the amount of pain they would experience after surgery during their hospitalization. These findings would support more education for patients regarding realistic expectations for pain that they may experience post-surgery, specifically after the femoral nerve block has worn off if this anesthetic approach will be used to control pain.

\section{Having Good Communication with Health Care Providers}

Some patients and health care professionals have found communication between all members of the patient-provider relationship to be inadequate following THR and TKR. ${ }^{34}$ Participants in this study experienced open and thorough communication between staff and patients, which contradicts findings from previous research. Participants felt that all of their needs were sufficiently met during their hospital stay. In fact, Samantha stated: "They've got everything set up and ready. I don't know what more they could have done for me." Interactions with staff has been identified in other research studies to influence confidence and preparedness

(C) The Internet Journal of Allied Health Sciences and Practice, 2017 
for discharge.4,18 The more positive these interactions and the more competent staff were perceived to be, the more confident patients felt for discharge. These same features were identified by this study to increase readiness for discharge home. Members of the health care team, including occupational therapy, should develop strong rapport with their clients using open, clear communication to increase confidence and discharge readiness after TKR.

\section{Preparing for the Post-Surgical Phase}

Numerous research studies have identified patient concerns about returning to valued occupations post THR and TKR surgery. $5,9,33,35,36 \mathrm{~A}$ study conducted to identify patient concerns in the early weeks following TKR found that basic self-care activities were more of a concern during the first week after TKR, and then participation in higher level activities became the main concern during the following weeks. ${ }^{36}$ Participants in this current study revealed many things they did preoperatively to prepare for life after surgery, such as cooking and freezing meals or hiring help to complete home maintenance tasks post-surgery. It is interesting to note that patients in this study were concerned with higher level occupations, such as cooking and cleaning, even before their surgeries. One evidence-based occupational therapy program found that patients who participated in education and training after surgery related to higher level activities, such as cooking and cleaning, felt more prepared to complete these tasks at home after THR and TKR surgery than patients who did not receive this training. ${ }^{37}$ Given patient interest in preparing for these valued occupations, these would be areas for occupational therapy to address through education and training both before and after TKR surgery.

\section{LIMITATIONS}

This was a small study to explore the experiences of these patients, and the results are not intended to be generalizable to all persons undergoing TKR surgery. However, results from this study may be transferrable for patients who undergo TKR in similar facilities as the study setting. Readers should consider their hospital setting, pre-operative education programs, post-operative services including therapy, typical length of stay, and patient population to determine if the results can be transferred to their facility. Further research is needed to determine if the patient experiences from this study are common and to examine the impact of any alterations made to client care as a result of this study to support readiness for return to home. The primary researcher was a PRN occupational therapist at the study setting. The primary researcher did not recruit participants or complete data collection during timeframes when she was scheduled to work to allow participants to speak openly and honestly about their discharge experiences. While this process was implemented to limit the influence of the researcher on participant responses, eligible participants who may have revealed valuable insights about the experience of preparing for discharge home could have been excluded from the study.

Patient recruitment was a significant issue in this study. Staffing changes and therapists transitioning to different units within the hospital resulted in the gatekeeper changing multiple times throughout the study, which caused delays in recruitment to allow for proper training of new research personnel. As a result of an increased patient caseload at the facility during the time of the study, and some surgeries that were scheduled later in the day, initial evaluations for new patients following TKR were sometimes completed the day after surgery. The day after surgery was often the day of discharge due to short lengths of stay common after TKR surgery in the United States. This did not allow the researcher enough time to interview patients prior to their return to home. Some patients who were initially interested in participating in the study later refused because of increased pain or nausea that often accompanies orthopedic surgery. Many eligible participants were likely missed because of the factors discussed above, and thus low participant recruitment may have prevented data saturation. Four patients total were recruited for participation in the study; additional participants were unable to be recruited following extension of the project with IRB approval. Although the four participants did provide similar data, having one or two additional participants could have confirmed the themes or revealed additional information.

The timing and depth of interviews was another limitation. Interviewing patients soon after TKR surgery meant patients could feel ill or tired, which may have impacted their responses. The short length of stay left little time for interviews. Interviews only occurred during the patient's hospital stay, but adding interviews after discharge home could have revealed information patients forgot to mention during their interview in the hospital or how their perceptions changed once returning to their home environment. Several studies have revealed that many patients have overly optimistic expectations about how well they will function after THR and TKR. ${ }^{5,32,34}$ Discrepancies in expectations compared to the reality of how clients actually function at home could be revealed through a secondary interview after discharge.

The barriers to clinical research experienced in this study are similar to those discussed in the literature. When providers in integrative health care clinics were interviewed, they expressed that the nature of the patient population as well as staff turnover impeded research activities within this setting..$^{38}$ Logistical challenges limited scholarship as well, as implementing research altered the typical daily routine for health care providers and impacted their ability to complete their other work responsibilities. Occasionally, gatekeepers ran out of time to talk about the research study during the initial occupational therapy evaluation and

(C) The Internet Journal of Allied Health Sciences and Practice, 2017 
they did not always have time to go back to the patient to discuss the study later, which may have reduced the sample size. Sometimes gatekeepers were also delayed in being able to contact the researcher about potential participants because of their work responsibilities and therapy schedules. This delay may have resulted in the researcher not having time to interview potential participants prior to their discharge home. Patient recruitment has been found to be the highest reported difficulty cited by many clinical researchers, and this was also found to be a barrier for completing this current study. ${ }^{39}$ Conducting research within clinical settings can reveal important information about a phenomenon being studied, however there are many barriers that can interfere with the research process.

\section{SUMMARY}

This study highlighted the experience of preparing for discharge home following TKR surgery for four patients with planned discharge to home from the hospital. Three main themes were identified: being supported for discharge home; having confidence in self, family and health care staff; and persevering: overcoming obstacles. Implications for health care providers including occupational therapy were discussed for both preoperative and postoperative recommendations to increase readiness for surgery and recovery following TKR.

DECLARATION OF INTEREST: The first author is employed at the study setting as a PRN occupational therapist. The second author does not have an affiliation with the study setting. The authors alone are responsible for the content and writing of this paper.

\section{REFERENCES}

1. The burden of musculoskeletal diseases in the United States (BMUS). United States Bone and Joint Initiative [Internet]. The Association; c2013-2016 [cited 2016 September 21]. Retrieved from: http://www.boneandjointburden.org/

2. Kurtz SM, Ong KL, Lau E, Bozic KJ. Impact of the economic downturn on total joint replacement demand in the United States: Updated projects to 2021. J Bone Joint Surg AM. 2014;96a(8):624-30. doi: 10.2106/JBJS.M.00285 [PMID: 24740658]

3. Jones A, Voaklander DC, Suarez-Almazaor ME. Determinants of function after total knee arthroplasty. Phys Ther. 2003;83: 696-706. [PMID: 12882610]

4. Cain $\mathrm{CH}$, Neuwith E, Bellows J, Zuber C, Green J. Patient experiences of transitioning from hospital to home: an ethnographic quality improvement project. J Hosp Med. 2012;7(5):382-7. doi: 10.1002/jhm.1918 [PMID: 22378714]

5. Showalter A, Burger S, Salyer J. Patients' and their spouses' needs after total joint arthroplasty: A pilot study. Orthop Nurs. 2000;19(1):49-57:62. [PMID: 110662624]

6. Hiyama Y, Okada S. Risk of fall in patients during the early months after total knee arthroplasty. J Arthritis. 2014;3(4):139. http://dx.doi.org/10.4172/2167-7921.1000139.

7. Swinkels A, Newman JH, Allain TJ. A prospective observation study of falling before and after total knee replacement surgery. Age Ageing. 2009;38:175-81. doi: 10.1093/ageing/afn229 [PMID: 19029071]

8. Cram P, Lu X, Kates SL, Singh JA, Li Y, Wolf BR. Total knee arthroplasty volume, utilization, and outcomes among Medicare beneficiaries, 1991-2010. JAMA. 2012;308(12):1227-36. [PMID: 23011713]

9. Barksdale P, Backer J. Health-related stressors experienced by patients who underwent total knee replacement seven days after being discharged home. Orthop Nurs. 2005;24(5):336-42. [PMID: 16272912]

10. Woolhead GM, Donovan JL, Dieppe PA. Outcomes of total knee replacement: A qualitative study. Rheumatology (Oxford). 2005;44(8):1032-7. [PMID: 15870149]

11. McGinley A. Factors affecting length of stay following total knee replacement: A clinical practice audit. Journal of Orthopedic Nursing. 2008;12:171-8.

12. Napier RJ, Spence D, Diamond O, O'Brien S, Walsh T, Beverland DE. Modifiable factors delaying early discharge following primary joint arthroplasty. Eur J Orthop Surg and Traumatol. 2012;23:665-9. doi: 10.1007/s00590-012-1053-5 [PMID: 23412186]

13. Ong PH, Pua $\mathrm{YH}$. A prediction model for length of stay after total and unicompartmental knee replacement. Bone Joint $\mathrm{J}$. 2013;95-B(11):1490-6. doi: 10.1302/0301-620X.95B11.31193 [PMID: 24151268]

14. Guerra ML, Singh PJ, Taylor NF. Early mobilization of patients who have had a hip or knee joint replacement reduces length of stay in hospital: A systematic review. Clin Rehabil. 2015;29(9):844-54. doi: 10.1177/0269215514558641 [PMID: 25452634]

15. Hass $\mathrm{S}$, Jaekel $\mathrm{C}$, Nesbitt $B$. Nursing strategies to reduce length of stay for persons undergoing total knee replacement: Integrative review of key variables. J Nurs Care Qual. 2015;30(3):283-8. doi: 10.1097/NCQ.00000000000000104 [PMID: 25485792]

16. Essving P, Axelsson K, Kjellberg J, Wallgren O, Gupta A, Lundin A. Reduced morphine consumption and pain intensity with local infiltration analgesia (LIA) following total knee arthroplasty. Acta Orthop. 2010;81(3):354-60. doi: 10.3109/17453674.2010.487241 [PMID: 20450425] 
17. Hunt GR, Hall GM, Murthy BVS, O'Brien S, Beverland D, Lynch MC, Salmon, P. Early discharge following hip arthroplasty: Patients' acceptance masks doubts and concerns. Health Expect. 2009;12:130-7. doi: 10.1111/j.1369-7625.2008.00522.x [PMID: 19320753]

18. Heine J, Koch S, Goldie P. Patients' experiences of readiness for discharge following total hip replacement. Aust J Physiother. 2004;50(4):227-33. [PMID: 15574111]

19. Perry MA, Hudson HS, Meys S, Norrie O, Ralph T, Warner S. Older adults experiences regarding discharge from hospital following orthopaedic intervention: A metasynthesis. Disabil Rehabil. 2012;34(4):267-78. doi: 10.3109/09638288.2011.603016 [PMID: 21981113]

20. Creswell JW. Qualitative Inquiry and Research Design: Choosing among five approaches. $3^{\text {rd }}$ ed. Thousand Oaks (CA): SAGE Inc.;2013.

21. Moustakas C. Phenomenological Research Methods. Thousand Oaks (CA): SAGE Publications, Inc.;1994.

22. Starks H, Trinidad SB. Choose your method: a comparison of phenomenology, discourse analysis, and grounded theory. Qual Health Res. 2007;17(10);1372-80. doi: 10.1177/1049732307307031 [PMID: 18000076]

23. Mero-Jaffe I. 'Is that what I said?' Interview transcript approval by participants: An aspect of ethics in qualitative research. International Journal of Qualitative Methods. 2011;10(3);231-47. doi:10.1177/160940691101000304

24. Tan C, Loo G, Pua YH, Chong HC, Yeo W, Ong PH, Lo MN, Allison G. Predicting discharge outcomes after total knee replacement using the Risk Assessment and Predictor Tool. Physiotherapy. 2014;100(2):176-81. doi: 10.1016/j.physio.2013.02.003 [PMID: 23830717]

25. Lucas B, Cox C, Perry L, Bridges J. Pre-operative preparation of patients for total knee replacement: An action research study. International Journal of Orthopaedic and Trauma Nursing. 2013;17(2):79-90. doi:10.1016/j.jjotn.2012.08.005

26. McDonald S, Hetrick S, Green S. Pre-operative education for hip or knee replacement. Cochrane Database Syst Rev. 2004;1. doi:10.1002/14651858.CD003526.pub2 [PMID: 14974019]

27. McDonald S, Page MJ, Beringer K, Wasiak J, Sprowson A. Preoperative education for hip or knee replacement. Cochrane Database Syst Rev. 2014;13(5). doi: 10.1002/14651858.CD003526.pub3 [PMID: 24820247]

28. Spalding J. Reducing anxiety by pre-operative education: Making the future familiar. Occup Ther Int. 2003;10(4):278-93. [PMID: 146457541]

29. Kearney M, Jennrich MK, Lyons S, Robinson R, Berger B. Effects of preoperative education outcomes after joint replacement surgery. Orthop Nurs. 2011;30(6):391-6. doi: 10.1097/NOR.0b013e31823710ea [PMID: 22124192]

30. Chen S-R, Chen C-S, Lin P-C. The effect of educational intervention on the pain and rehabilitation performance of patients who undergo a total knee replacement. J Clin Nurs. 2014;23(1-2):279-87. doi: 10.1111/jocn.12466 [PMID: 24313941]

31. Jones S, Alnaib M, Wilkinson M, St Clair Gibson A, Kader D. Pre-operative patient education reduces length of stay after knee joint arthroplasty. Ann R Coll Surg of Engl. 2011;93(1):71-5. doi: 10.1308/003588410X12771863936765 [PMID: 21418755]

32. Fielden JM, Scott S, Horne JG. An investigation of patient satisfaction following discharge after total hip replacement surgery. Orthop Nurs. 2003;22(6):429-36. [PMID: 14705473]

33. Jacobson AF, Myerscough RP, DeLambo K, Fleming E, Huddleston AM, Bright N, Varley JD. Patients' experiences on total knee replacement: A qualitative study sheds light on pre- and postoperative experiences. Am J Nurs. 2008;108(5):54-63. doi: 10.1097/01.NAJ.0000318000.62786.fb [PMID: 18434802]

34. Westby MD, Backman CL. Patient and health professional views on rehabilitation practices and outcomes following total hip and knee arthroplasty for osteoarthritis: A focus group study. BMC Health Serv Res. 2010;10:119. doi: 10.1186/1472-696310-119 [PMID: 20459834]

35. Macario A, Schilling $P$, Rubio R, Bhalla A, Goodman, S. What questions do patients undergoing lower extremity joint replacement surgery have? BMC Health Serv Res. 2003;3(1):11. doi: 10.1186/1472-6963-3-11 [PMID: 12823860]

36. Rastogi R, Davis AM, Chesworth BM. A cross-sectional look at patient concerns in the first six weeks following total knee arthroplasty. Health Qual Life Outcomes. 2007;5:48. doi: 10.1186/1477-7525-5-48 [PMID:17678532]

37. Crum KR. Readiness for discharge: Occupation-based treatment in the orthopedic setting. OT Practice. 2011;16 (14):14-8, 23.

38. Verhoef MJ, Mulkins A, Kania A, Findlay-Reece B, Mior S. Identifying the barriers to conducting outcomes research in integrative health care clinics- a qualitative study. BMC Health Serv Res. 2010;10:14. doi: 10.1186/1472-6963-10-14 [PMID: 20074354]

39. Cullati S, Courvoisier DS, Gayet-Ageron A, Haller G, Irion O, Agoritsas T, Rudaz S, Perneger TV. Patient enrollment and logistical problems top the list of difficulties in clinical research: a cross-sectional survey. BMC Med Res Methodol. 2016;16(1):50. doi: 10.1186/s12874-016-0151-1 [PMID: 27145883] 